\title{
MÁS ALLÁ DEL GRIMEN ORGANIZADO: LA REFORMULACIÓN DEL CONCEPTO DE INSURGENCIA Y SU IMPACTO EN EL ENTORNO ESTRATÉGICO SUDAMERICANO
}

\author{
Mariano César Bartolomé ${ }^{1}$
}

La criminalidad organizada en América Latina y la reformulación del concepto de Insurgencia

En materia de seguridad, América Latina muestra un escenario que se presenta como contradictorio, según cuál sea la lente con el cual se lo analice. Desde un punto de vista tradicional, de clara raíz westfaliana, en el cual las cuestiones de seguridad se enmarcan en dialécticas interestatales y se expresan en clave militar, la realidad hemisférica es verdaderamente excepcional. Sin embargo, la situación es mucho menos placentera cuando se aborda la seguridad en términos no convencionales.

En el plano tradicional de la seguridad, la instauración y consolidación de regímenes democráticos en toda la región permitió que la gran mayoría de los diferendos territoriales persistentes de otras épocas, y que constituían concretos casus belli, se encauzaran al plano de la resolución negociada por medios diplomáticos. Acompañando este proceso, múltiples Medidas de Construcción de Confianza y Seguridad (CSBMs) de diferente tipo contribuyeron a que antiguas relaciones bilaterales de desconfianza signadas por rivalidades geopolíticas, se transformaran en vínculos de tipo cooperativo e iniciativas integracionistas comunes.

1 Universidade de Salvador (USAL)/ Universidad Nacional de Lanús (UNLa)/Universidad de Buenos Aires (UBA). E-mail: marianobartolome@yahoo.com.ar 
En este contexto es menester señalar el avance registrado en América del Sur, región que se concibe a sí misma como una Zona de Paz, en referencia a un área geográfica donde los Estados miembros reflejan valores compartidos (incluida la democracia, entre otros) y se comprometen a no competir entre sí en términos de realpolitik ${ }^{2}$. Esa posición fue oficialmente adoptada a mediados del año 2002 en ocasión de la Segunda Reunión de Presidentes de la región, realizada en Guayaquil, de conformidad con los principios de la Organización de las Naciones Unidas (ONU) y la Organización de Estados Americanos (OEA), tomando como antecedentes a acuerdos multilaterales celebrados por la Comunidad Andina de Naciones (CAN) y el Mercado Común del Cono Sur (Mercosur).

Es justo señalar que este escenario se vio dramáticamente alterado por la crisis que se desató el primero de marzo de 2008 cuando Colombia ejecutó la operación militar conjunta "Fénix" contra un campamento de las Fuerzas Armadas Revolucionarias de Colombia (FARC) ubicado en Angostura, un paraje del norte ecuatoriano cerca de la frontera común. Ese incidente inició una etapa álgida en las relaciones entre Colombia, Ecuador y sobre todo Venezuela, de aproximadamente dos años duración. En su transcurso desde la Casa de Nariño se acusó reiteradamente al régimen bolivariano de colaborar con las FARC, mientras en sentido inverso se calificaba como un acto belicista la autorización para que EEUU utilice algunas de sus instalaciones militares.

No obstante su gravedad, la crisis mencionada tuvo una consecuencia positiva, la constitución del Consejo de Defensa Sudamericano (CDS), la primera arquitectura de seguridad multilateral gestada en la región en toda su historia. En una reunión celebrada en Lima en mayo del año 2011, el Consejo ratificó el avance logrado en Guayaquil casi un decenio antes, confirmando el carácter de Zona de Paz para América del Sur.

Contrariamente a lo que se sostiene desde perspectivas realistas ortodoxas que enfatizan en el balance de poder, esta situación no se ve alterada por el innegable aumento de los gastos de armamento que se registraron en el

${ }^{2}$ Zalmay Khalilzad, "Losing the Moment? The United States and the World after the Cold War," in Order and Disorder after the Cold War, ed. Brad Roberts. (Cambridge \& London: The MIT Press, 1995), 57-77. 


\section{Mariano César Bartolomé}

área en los últimos años, vinculados sobre todo a las erogaciones de Brasil, Colombia, Chile y Venezuela. En este espacio geográfico no se observan carreras armamentistas y sus expendios en este rubro son inferiores al $2 \%$ de su Producto Interno Bruto, los menores del mundo en términos relativos. Es cierto que persiste un "dilema de seguridad" en el vínculo Chile-Perú ${ }^{3}$, pero tanto la OEA a partir de su XL Asamblea General (junio 2010) como el CDS desde su Reunión Extraordinaria en noviembre de 2011, han asumido la responsabilidad de diseñar mecanismos para transparentar los gastos de armamento y evitar ese tipo de percepciones.

El positivo escenario de seguridad que se describe en los párrafos anteriores coexiste con una situación mucho más complicada en materia de amenazas no convencionales a la seguridad, un plano en el cual el hemisferio pierde sus ventajas relativas para integrarse a un tablero global inestable y volátil, con altos niveles de incertidumbre.

Las amenazas no convencionales a la seguridad reconocen apenas tres regularidades: sus protagonistas son actores no estatales; no siempre emplean la violencia como herramienta racional de política y, en caso de usarla, lo hacen fuera de los formatos tradicionales asociados a la lógica clausewitziana, incursionando en lo que usualmente se conoce como asimetría. Más allá de esos elementos, esta esfera se caracteriza por su heterogeneidad, que se incrementa por diferentes procesos de securitización ${ }^{4}$, dando lugar a una situación que fue simbólicamente definida como "incertidumbre estratégica" o "mundialización del miedo". Es decir, una permanente percepción de inseguridad que alcanza a todos los individuos, sin que puedan evitarlo, en la cual los peligros y amenazas no reconocen una fuente clara ni limitaciones territoriales o políticas a su $\operatorname{accionar}^{5}$.

\footnotetext{
${ }^{3}$ En una situación de ese tipo, las decisiones que adopta una nación en el ejercicio soberano de su derecho a dotarse de los medios que la hagan sentir segura involuntariamente (y allí reside la paradoja) generan inseguridad en un país vecino; en otras palabras, la "búsqueda de seguridad" que lleva adelante el primero de esos actores, es interpretada por el restante como una mera "búsqueda de poder".

${ }^{4}$ Desde una perspectiva constructivista, la "securitización" es un proceso discursivo y político mediante el cual una comunidad política decide tratar algo como una amenaza hacia un objeto de referencia valuado, habilitando la adopción de medidas urgentes y excepcionales para contrarrestar tal amenaza.

5 Ángel Tello, "La Incertidumbre Estratégica,", in Seguridad y Defensa em tiempos de Bicentenario. Visiones desde Argentina y Chile, comp. Mariano Bartolomé. (Buenos Aires: Instituto de Publicaciones
} 
Dentro de la agenda no convencional de la seguridad se insertan las amenazas transnacionales, cuya dinámica -como cualquier proceso de esa naturaleza- trasciende los límites de un Estado para alcanzar a dos o más unidades políticas de ese tipo. Estos fenómenos también suelen ser denominados "nuevas amenazas", una idea errónea que induce a confusiones pues, con alguna excepción puntual asociada a la cuestión cibernética, tales cuestiones no son nuevas en la arena global; en todo caso, difieren de antaño algunas de sus características, como también ha cambiado la importancia adquirida en la agenda externa de los Estados.

No existe en el ámbito de la Seguridad Internacional un listado cerrado de amenazas transnacionales, ni mucho menos una jerarquización según su importancia. Esto es así porque los contornos de estos fenómenos son difusos, se utilizan diferentes enfoques para analizarlos, y su gravedad varía de acuerdo a criterios espaciales y temporales. De todas maneras es necesario intentar una identificación básica pues, como dice el intelectual español Manuel Vázquez Montalbán, "poner nombre a lo que nos lastima nos ayuda a defendernos"\%. En este sentido, dentro del inventario de amenazas transnacionales presentes en América Latina se destaca la criminalidad organizada bajo diferentes manifestaciones.

Es usual que la cuestión criminal se vincule (sobre todo en casos de expansión, aumento y profundización de su accionar) de manera directa con la cuestión de la gobernabilidad, cuyo deterioro más allá de ciertos niveles puede dar lugar a una erosión de la capacidad estatal para ejercer autoridad sobre todo el territorio y monopolizar la violencia, de manera efectiva. La lógica de este vínculo es que en un proceso como el descripto, sintomático de una "fragilización" del Estado7, la pérdida de control sobre espacios geográficos cada

Navales, 2010), 21-34; Natalie Pabón Ayala, "Las relaciones cívico-militares en la Política de Seguridad Democrática", in Perspectivas actuales de la Seguridad y la Defensa en Colombia y América Latina, ed. Alejo Vargas Velásques. (Bogotá: Universidad Nacional de Rosario, 2008), 51-64.

6 Manuel Vázquez Montalbán, "Prólogo. Notas sobre globalizadores y globalizados", in Geopolitica Del Caos, multiple authors. (Barcelona: Le Monde Diplomatique/Temas de Debate, 1999), 15.

7 Susan Woodward, "Fragile States: Exploring the Concept", Fundación para las Relaciones Internacionales y El Diálogo Exterior (FRIDE), 16 de diciembre de 2006. http://www.fride.org/publication/97/fragile-states:-exploring-the-concept 


\section{Mariano César Bartolomé}

vez más amplios los torna atractivos para el asentamiento de organizaciones vinculadas con la criminalidad e incluso el terrorismo, que pueden desplegar sus actividades desde esos lugares.

En cuanto a la criminalidad organizada, América Latina se encuentra plenamente inserta en los esquemas globales de esta amenaza transnacional cuyas dimensiones son verdaderamente enormes: en el documento final de la Comisión Latinoamericana sobre Drogas y Democracia, creada por tres ex presidentes de la región, se identifican cuatro características distintivas del crimen organizado latinoamericano: (i) su aumento cuantitativo, tanto por el tráfico internacional como por el control de los mercados domésticos por parte de los grupos en pugna; (ii) el crecimiento de la violencia, que alcanza a todos los sectores de la sociedad; (iii) la proliferación de vínculos con la esfera política y la infiltración en las instituciones democráticas; finalmente, (iv) la corrupción de los funcionarios públicos, con especial énfasis en miembros de los organismos de seguridad y policiales ${ }^{8}$.

Según datos de la OEA, la violencia criminal tiene en América Latina carácter "pandémico" y le cuesta a sus ciudadanos más de US\$16 mil millones anuales; por otro lado, la región tiene apenas el $8 \%$ de la población mundial, pero acapara más del $40 \%$ de los homicidios y casi el $70 \%$ de los secuestros extorsivos que se cometen en el planeta cada año ${ }^{9}$. De acuerdo a evaluaciones de una ONG especializada en violencia urbana, 24 de las 25 ciudades más violentas del mundo son latinoamericanas, con la única excepción de la estadounidense New Orleans en el vigésimo primer lugar. La lista la encabeza la hondureña San Pedro Sula con una tasa de homicidios superior a 159 casos cada 100 mil habitantes (159/00000), seguida por Ciudad Juárez en México con 148/000001011.

\footnotetext{
${ }^{8}$ Comisión Latinoamericana sobre Drogas y Democracia. Drogas y Democracia: hacia un cambio de paradigma. (Rio de Janeiro: Viva Río \& Comisión Latinoamericana sobre Drogas y Democracia, 2009 ), 7. ${ }^{9}$ Cifras emitidas por el Secretario General de la esa organización, José Miguel Insulza, en julio de 2009, en su intervención en la Conferencia Interamericana de Seguridad Pública celebrada en Montevideo. In Mariano Bartolomé, "Situación del Crimen Organizado en América Latina", Ágora Internacional 10 (2009): 16-20.

${ }^{10}$ El reporte también indica que 5 de las 10 ciudades más violentas del mundo son mexicanas; 45 de las 50 ciudades más violentas se sitúan en el continente americano y 40 en América Latina; la jurisdicción subnacional más violenta del mundo corresponde a Honduras y 3 de las 10 jurisdicciones subnacionales más violentas del mundo son hondureñas; y que 19 de las 50 jurisdicciones nacionales más violentas del
} 
Existen autores que hablan de las "cinco guerras de la globalización" en referencia a idéntica cantidad de expresiones predominantes del crimen organizado contemporáneo: los tráficos ilegales de drogas, armas, personas, propiedad intelectual $\mathrm{y}$ dinero ${ }^{12}$. Las tres primeras han sido denominadas "transacciones transfronterizas de alto valor" por un especialista en la materia ${ }^{13}$, un concepto que no compartimos pues el "valor" de una transacción transfronteriza ilegal determinada varía según el lugar y el momento, no siendo conveniente acotarla a tres tipos de tráficos en particular.

En América Latina se encuentran esas cinco manifestaciones de criminalidad, y también otras como el contrabando de los bienes más diversos, o los tráficos de fauna, biodiversidad y piedras preciosas. Pero no están presentes con igual intensidad. Nítidamente se destacan por su gravedad tanto la producción y tráfico ilícitos de drogas, como el tráfico de armas pequeñas y livianas. La importancia clave que juegan estos flagelos dentro del mapa del crimen organizado latinoamericano también se comprueba en un exhaustivo relevamiento de la Oficina de las Naciones Unidas para la Droga y el Delito (UNODC, sigla en inglés) que se concentró en cinco flujos transnacionales ilegales en particular: cocaína, heroína, armas pequeñas y livianas, migrantes y trata de personas ${ }^{14}$.

En materia de tráfico de armas, de acuerdo a cifras proporcionadas hace unos años por la entidad no gubernamental $O_{x} f a m$, existen actualmente casi

mundo se ubican en México y en Centroamérica. Para mayores datos, ver: Consejo Ciudadano para la Seguridad Pública y la Justicia Penal, Metodología del ranking (2011) de las 50 ciudades y las 50 jurisdicciones subnacionales más violentas del mundo. (México DF: CCSP, 2012)

${ }^{11}$ De acuerdo a algunas lecturas, la verdadera tasa de homicidios de Ciudad Juárez es mucho más alta que lo indicado por los guarismos oficiales, y de hecho sería la más alta del mundo: 191 casos cada 100 mil habitantes. Ver: “Criminalidad y violencia en América Latina iniciando la segunda década del Siglo XXI", Informes Del GERIUP(11 de enero de 2012).

12 Charles Lutes, Elaine Bunn y Stephen Flanagan, "The Emerging Global Security Environment", in Strategic Challenges. America's Global Security Agenda, de Stephen Flanagan y James Schear. (Washington DC: National Defense University Press \& Potomac Books, 2008), 1-19.

13 El concepto corresponde a Moisés Naím y fue tomado de: Ivan Briscoe, "Crimen y drogas en los Estados frágiles", Fundación para las Relaciones Internacionales y el Diálogo Exterior (FRIDE), 20 de julio de 2007, http:/www.fride.org/publicacion/151/crimen-y-drogas-en-los-estados-fragiles

${ }^{14}$ UNODC, The Globalization of Crime. A Transational Organized Crime Threat Assessment. (Vienna: UNODC, 2010). 


\section{Mariano César Bartolomé}

700 millones de armas ligeras en circulación en todo el mundo, lo que representa una por cada diez habitantes, aproximadamente. Casi el $60 \%$ de estas armas están en manos de civiles, mientras una cuarta parte de ellas es vendida en mercados ilegales o contrabandeada, lo cual significa que van a parar a manos de delincuentes, grupos insurgentes y criminales ${ }^{15}$. En base a esas cifras se podría suponer que América Latina concentra casi la mitad de las armas ilegales en circulación a nivel global, si se toman por ciertas las estimaciones del Centro para la Información de Defensa (DIC, sigla en inglés) de Washington, quien las calculó en más de 80 millones $^{16}$.

Respecto al tema de las drogas, América del Sur juega un rol clave: sin tomar en cuenta volúmenes marginales de heroína y cannabis, el subcontinente es responsable por la totalidad de la cocaína que se produce a nivel mundial. En su último reporte anual, la UNODC consigna que la superficie dedicada a los cultivos ilegales asociados a esa droga rondó las 153,7 mil hectáreas en el año 2011, de las cuales 64 mil se ubican en Colombia, el equivalente a $41,6 \%$ del total; 62,5 mil en Perú (40,7\%); y 27,2 mil en Bolivia (17,7\%).

La cocaína generada por esas tres naciones andinas constituye la punta de un iceberg de dimensiones globales. El cultivo ilegal de la hoja coca; su procesamiento empleando diferentes precursores químicos; su transporte por diferentes medios, trasiego y almacenamiento; su venta a grandes distribuidores y su comercialización al consumidor; el pago de servicios de protección para asegurar cada una de esas fases; y la corrupción de funcionarios públicos configuran en conjunto un negocio multimillonario. Basta considerar que los cultivadores de coca, campesinos de escasos recursos y bajo nivel educativo, suelen recibir entre US\$ 300 y US\$ 500 a cambio de la cantidad de hojas necesarias para producir un kilogramo de cocaína. Esa cocaína saliendo de Colombia cuesta alrededor de US\$ 1 mil, en Guatemala se cotiza en US\$ 13 mil, en EEUU en US\$ 30 mil y en Europa puede llegar a cotizar más de US\$ 160

\footnotetext{
15 Estos datos fueron vertidos en la Conferencia de las Naciones Unidas sobre el Tráfico de Armas Pequeñas y Ligeras (SALW, sigla en inglés), que sesionó en Nueva York entre junio y julio de 2006. El evento permitió conocer en detalle y de manera actualizada esta problemática, responsable de la mayoría de las muertes por violencia armada en el mundo.

${ }^{16}$ Fernando Gualdoni y Javier Lafuente, "Las armas ilegales desangran Latinoamérica", El País (25 de mayo de 2009).
} 
mili ${ }^{17}$. Aunque no se conoce con certeza el monto de estos ilícitos, la UNODC calcula esa cifra entre US\$ 75 mil millones y US\$ 100 mil millones anuales ${ }^{18}$.

Más allá del marco sudamericano, aunque se observa un crecimiento de la importancia de Europa como mercado de consumo de la cocaína generada en los países andinos, que se ha duplicado en los últimos años, el primer lugar sigue correspondiendo a EEUU, acaparando el 36\% de la producción mundial, o sea unas 157 toneladas. El largo camino de la cocaína sudamericana hacia su principal mercado de consumo ayuda a entender buena parte de la violencia que se observa en el resto del hemisferio, pues en su tránsito con rumbo norte atraviesa el istmo y México. Se estima que más del 80 \% de la cocaína que discurre por tierras mexicanas y centroamericanas se orienta hacia el mercado estadounidense, y casi el $20 \%$ restante al Viejo Continente.

En América Central, el tráfico de la cocaína procedente de los países andinos involucra, en su tránsito hacia el mercado estadounidense, tanto a carteles mexicanos (vide infra) como pandillas y "maras" locales, que suman más de 70 mil miembros. De esa manera contribuye a un deterioro tan drástico de las condiciones de seguridad de la región, que según el Banco Mundial socava las esperanzas de paz y estabilidad que surgieron luego de la resolución de sus guerras civiles ${ }^{19}$. De acuerdo al primer Reporte Mundial sobre Homicidios divulgado el año pasado por la UNODC, el Caribe y América Central constituyen las únicas regiones del mundo donde el número de homicidios creció respecto a 1995. De hecho, con 6,2 mil asesinatos en una población de 7.7 millones (tasa de asesinatos de 82/00000), Honduras se constituye en el país más violento del mundo, seguido por El Salvador con 4 mil homicidios para una población de 6,1 millones de habitantes ${ }^{20}$.

Avalando estos datos cuantitativos Douglas Fraser, jefe del Comando Sur estadounidense, declaró a comienzos del año pasado que el área centroamericana "probablemente se haya transformado en la zona más

17 "La Conferencia Internacional de Apoyo a la Estrategia de Seguridad de Centroamérica", Informes del GERIUP(29 de junio de 2011)

${ }^{18}$ UNODC, World Drug Report. (Vienna: UNODC, 2011), 85-126.

${ }^{19}$ Banco Mundial, Crimen y Violencia en Centroamérica. Un Desafio para el Desarrollo. (Washington DC: World Bank, 2011).

${ }^{20}$ UNODC, 2011 Global Study on Homicide. Trends, Context, Data. (Viena: UNODC, 2011) 


\section{Mariano César Bartolomé}

mortalmente peligrosa ("deadliest") del planeta, fuera de Irak y Afganistán" 21 . Convalidando esa contundente apreciación, las tasas de homicidios en algunas ciudades de la región, como la mencionada San Pedro Sula en el norte de Honduras, equivalen a las que se registran en Mogadisco (Somalia) o en la localidad afgana de Kandahar.

Una situación análoga se observa en México, donde el protagonismo del tráfico de drogas hacia EEUU recae en seis grandes carteles que operan en territorio azteca (el de Sinaloa; el de Juárez; el de Tijuana; el del Golfo; la Familia Michoacana -hoy al borde de su desaparición- y Los Zetas), complementados por muchos otros grupos menos conocidos pero igualmente importantes (entre ellos la Línea, los Aztecas, los Mexicas y los Caballeros Templarios). De acuerdo al reconocido especialista Edgardo Buscaglia, en la actualidad los grupos criminales mexicanos se ubican como los terceros más importantes a nivel mundial, dejando atrás a las mafias italianas y los carteles colombianos, y siendo superados solamente por las mafias rusas y las tríadas chinas, que se encuentran en primero y segundo lugar ${ }^{22}$.

Según estadísticas oficiales proporcionadas por la Procuraduría General de la República (PGR) mexicana, en apenas un lustro, desde que asumió la presidencia mexicana Felipe Calderón a fines del año 2006, hasta igual momento del año 2011, la violencia asociada a la criminalidad organizada produjo en tierra azteca casi 50 mil muertes, cifra a la que deben agregarse cerca de 1,5 millón de desplazados internos y 5,4 mil personas reportadas como desaparecidas ante la Comisión Nacional de Derechos Humanos. Los cálculos no oficiales elevan la cantidad de homicidios a más de $60 \mathrm{mil}$, según la siguiente progresión: en el último mes de 2006, 62 muertes; 2826 en 2007; 6837 en 2008; 11753 en 2009; 19546 en 2010 y 20646 en $2011^{23}$.

\footnotetext{
${ }^{21}$ Anna Mulrine, "Pentagon: Central America 'deadliest' non-war zone in the world", The Christian Science Monitor, April 11, 2011, http:/www.csmonitor.com/USA/Military/2011/0411/Pentagon-CentralAmerica-deadliest-non-war-zone-in-the-world.

${ }^{22}$ Buscaglia es un experto reconocido por la Organización de las Naciones Unidas (ONU), se desempeña como catedrático del Instituto Tecnológico Autónomo de México (ITAM) y dirige el Centro Internacional de Desarrollo Legal y Económico.

${ }^{23}$ M. M. Cascante, “60.000 muertos en la guerra contra la droga". ABC (Madrid) 26 de diciembre de 2011, http://www.abc.es/20111226/internacional/abcp-muertos-guerra-droga-20111226.html.
} 
De las más de 60 mil muertes asociadas a la criminalidad, el $80 \%$ se concentra en una docena de los 32 estados del país. En el primer lugar se sitúa Chihuahua, con 12,7 mil asesinatos, la mayor parte de ellos en Ciudad Juárez, que disputa el dramático lugar de urbe más violenta del mundo. La Comisión Estatal de Derechos Humanos de Chihuahua documentó 12 mil niños huérfanos en dicha ciudad fronteriza y más de 120 mil personas desplazadas a causa de la violencia. En segundo lugar figura Sinaloa, con 7 mil muertes, y en el tercer puesto Guerrero con 5,1 $\mathrm{mil}^{24}$.

Dentro de la oleada de violencia criminal que signó a la gestión presidencial de Calderón, probablemente el episodio más álgido se registró en agosto del 2011, cuando Los Zetas protagonizaron un atentado con explosivos a plena luz del día en un casino de Monterrey, ocasionando 60 víctimas fatales. Las palabras expresadas en esos momentos por el titular del Poder Ejecutivo mexicano reflejaron la dimensión de esos eventos:

"Es evidente que no estamos enfrentando a delincuentes comunes. Estamos frente a verdaderos terroristas que han superado no solamente los límites de la ley, sino del elemental sentido común y el respeto a la vida". ${ }^{25}$

El "Barómetro de Conflictos" que elabora la Universidad de Heidelberg proporciona un ejemplo elocuente de las percepciones vigentes en algunos centros académicos del llamado Primer Mundo sobre la gravedad del caso mexicano. Ya en el año 2010 la institución germana incluyó a México en el grupo de los seis Estados más peligrosos del planeta, con niveles de violencia sólo equiparables a los de Somalia, Sudán, Irak, Afganistán y Pakistán. En una escala que va de 1 a 5 , México fue calificado con el máximo puntaje, que equivale a "guerra". Esto significa, según el análisis, que el país vive "un

${ }^{24}$ GERIUP (2012): Criminalidad y violencia..., op.cit.

${ }^{25}$ Rubén Luis Ayala. “¿Es un ataque de los Zetas a EEUU sólo una cuestión de tiempo?” Agora, 19 de octubre de 2011, http://www.agorarevista.com/es/articles/rmim/features/online/2011/10/19/iran-zetasplot. 


\section{Mariano César Bartolomé}

conflicto en el que la fuerza violenta se usa de manera organizada y sistemática, y en el que la destrucción es masiva y de larga duración" 26.

Con un contexto como el descripto, han vuelto a recrudecer versiones que subrayan los severos problemas de gobernabilidad que las organizaciones criminales le generan al Estado mexicano, para especular con su "falla" a mediano plazo, si las condiciones no se revierten. Conviene recordar que este tipo de lecturas se inició a principios del año 2009 desde EEUU, cuando su Departamento de Defensa calificó a México como un "Estado fallido", al lado de Pakistán; poco después, un alto funcionario de la Agencia Central de Inteligencia (CIA) comentó que un probable colapso al sur de la frontera estaba en la lista de mayores preocupaciones de seguridad de la institución.

El gobierno de Calderón ha negado permanentemente esa imputación argumentando -desde nuestra perspectiva con razón- que en México no se registran por parte del Estado nítidas pérdidas de control de áreas geográficas de consideración en beneficio de contrincantes no estatales, característica clave de un proceso de "falla". Tampoco la perspectiva institucional proporciona sólido sustento a la idea de la "falla", ya que el fracaso se limitaría a una pequeña porción de las estructuras estatales federales; en concreto, aquellas vinculadas a las actividades de seguridad, inteligencia, policiales y de justicia ${ }^{27}$.

Sin embargo, en los últimos tiempos se registraron preocupantes avances en el despliegue territorial de las bandas criminales, tipificados como síntomas de una incipiente refeudalización que da por tierra con los logros de la Revolución con su correlato de desarme y desmovilización de grupos irregulares $^{28}$. Aunque aún no se detectan vastas áreas geográficas denegadas al Estado en un sentido tradicional, una investigación llevada adelante por el Senado de ese país hace un par de años sostuvo que los carteles controlarían totalmente (vía corrupción y cooptación de funcionarios) unas 195 alcaldías e

\footnotetext{
${ }^{26}$ Heidelberg Institute for International Conflict Research (HIIK), Conflict Barometer 2010. (Heidelberg: HIIK,2010). Disponible en: http:/www.hiik.de/en/konfliktbarometer/pdf/ConflictBarometer_2010.pdf

${ }^{27}$ Raúl Benítez Manaut, "La crisis de seguridad de México", Nueva Sociedad 220 (2009), 173-189; Jorge Villalobos, "La fuerza de México", Nexos, $1^{\circ}$ de marzo de 2009.

${ }^{28}$ Benítez Manaut, op.cit.
} 
influirían en otras 1536, las cuales suman el $71 \%$ del total de los 2439 municipios mexicanos.

En ciertos puntos focales especialmente relevantes desde el punto de vista de los tráficos ilegales, por su proximidad al territorio estadounidense, se multiplica la presencia de los grupos criminales, que libran encarnizados y prolongados enfrentamientos por su control.

A partir de tales avances es que la hipótesis de la falla estatal volvió a integrar el discurso de muchos especialistas, tanto nacionales como extranjeros, con una novedad: se incorpora al análisis la presunta existencia de una situación de insurgencia. Entre quienes adhieren a esta óptica se incluyen funcionarios estadounidenses, pese a que oficialmente la Casa Blanca clasifica a las organizaciones mexicanas dentro de la criminalidad transnacional ${ }^{29}$.

Ese fue el caso de Richard Lugar, el republicano de mayor jerarquía en la comisión de Relaciones Exteriores del Senado y uno de los miembros más influyentes del Capitolio, cuando declaró que la violencia asociada al crimen organizado en México había adquirido las características de una "narcoinsurgencia" porque los cárteles intentan limitar el control del gobierno en partes del país, convenciendo a la población de que la ofensiva militar y las reformas políticas del presidente Calderón son fútiles y, de hecho, la causa de la espiral de violencia.

Al protagonizar la primera referencia de importancia a la narcoinsurgencia mexicana, Lugar enfatizó en la creciente infraestructura de los carteles aztecas en EEUU, incluyendo redes de distribución, casas seguras y operaciones de lavado de dinero. En esos términos, sostuvo que el problema concierne de manera directa a la seguridad nacional de su país y solicitó a la administración Obama considerar la utilización de las Fuerzas Armadas y la comunidad de inteligencia para brindar más activos de vigilancia para ayudar a detener los tráficos transfronterizos ilegales con México. En este sentido, propuso "el despliegue de aviación, vigilancia y bienes de inteligencia conjunta" y "adaptar las tácticas para enfrentar las amenazas cambiantes del cártel" 30 .

\footnotetext{
29 "Definición de amenazas", Ágora 4 (2011): 10-13.

${ }^{30}$ J. Jaime Hernández, "Lugar: México tiene narcoinsurgencia”, El Universal, 27 de septiembre de 2010.
} 


\title{
Mariano César Bartolomé
}

Por esos momentos el ya citado Buscaglia aportó a esta cuestión opinando que la delincuencia organizada mexicana ya forma parte del Estado, estando presente en diferentes porciones del mismo. Textualmente:

\begin{abstract}
"Cuando uno habla que el Estado mexicano se ha fragmentado en su debilidad, quiere decir que diferentes fragmentos del Estado mexicano a nivel municipal o estatal, ya forman parte estructural del crimen organizado".
\end{abstract}

Este experto fue más allá de las clasificaciones convencionales para postular, en base a las referidas fragmentaciones en planos locales o regionales, una incipiente "afganización" del Estado; es decir, su ausencia en casi mil bolsones territoriales en donde los carteles criminales desestabilizaron o capturaron los gobiernos municipales, para continuar de esa forma sus negocios ilícitos. La analogía con la situación de Afganistán progresa hasta el punto de tipificar a las bandas criminales mexicanas como "mafia insurgencia", debido a que enfrentan al Estado de igual a igual y realizan complejos operativos similares a los que ejecutan los taliban para emboscar a tropas estadounidenses o de naciones aliadas ${ }^{31}$.

Casi dos años después de emitida la apreciación de Lugar esa visión continuaba gozando de vigencia y el mandatario civil número dos del Ejército estadounidense, Joseph Westphal, alegaba que los insurgentes criminales podían acabar controlando México. Al mismo tiempo, la propuesta del veterano senador de emplear nuevas armas y tácticas para enfrentar a los carteles encarnaba en varios municipios linderos con la frontera meridional, donde las policías locales solicitaron a sus autoridades políticas la provisión de: vehículos con blindaje; equipos militares de comunicación; armamento automático M-16, M-14 y lanzagranadas; aviones no tripulados (UAVs) y el entrenamiento correspondiente, incluyendo tácticas de combate.

De acuerdo al director del área de Seguridad Pública de Texas, quien ha reportado en numerosas ocasiones al Congreso estadounidense, el aumento y complejización de las actividades de los cárteles mexicanos en torno a la

31 "Cárteles controlan casi mil territorios del país, dice experto", Informador, 27 de junio de 2010. 
frontera común es la causa de los pedidos policiales, que en numerosos casos son satisfechos mediante donaciones del Departamento de Defensa ${ }^{32}$.

Desde el ámbito académico estadounidense también se formularon interpretaciones de la criminalidad organizada en términos de insurgencia. El think tank independiente Centro para una Nueva Seguridad en Estados Unidos (CNAS) publicó hace dos años un informe titulado "Guerras Criminales: Pandillas, Carteles y la Seguridad Nacional Estadounidense". En su desarrollo, indican que el crimen organizado "hace metástasis en una nueva insurgencia criminal organizada" que amenaza a los gobiernos y sociedades civiles del Hemisferio Occidental y, cada vez más, a EEUU ${ }^{33}$.

Uno de los autores del referido dossier sostuvo que en las insurgencias criminales, la búsqueda de ganancias (económicas) ocupa el lugar que en otras circunstancias corresponde a la ideología, la religión o la etnia. Y agrega que este reciente fenómeno erosiona y socava las instituciones políticas y las sociedades de los Estados democráticos a través de la corrupción y la violencia, persiguiendo el establecimiento de áreas geográficas donde puedan desplegar sus actividades en forma irrestricta.

En lo que atañe a EEUU, fuente de estos novedosos abordajes, se indica que las insurgencias criminales mexicanas constituyen una amenaza real a su bienestar, aunque el crecimiento y consolidación de estos actores no estatales los prefigura como potenciales amenazas directas a la seguridad nacional de la superpotencia. Esa apreciación se fundamenta de la siguiente manera:

"Los carteles mexicanos emplean operaciones psicológicas, fomentan las protestas antigubernamentales, atacan tanto a la policía como a las Fuerzas Armadas a través de asaltos de infantería, asesinan a políticos y periodistas, decapitan a sus víctimas para amplificar el impacto estratégico de sus ataques, y cooptan y corrompen a militares, policías y funcionarios públicos en todos los niveles de gobierno. El resultado es un bandolerismo extremo y un grupo de insurgencias criminales

32 "Criminalidad y violencia en América Latina iniciando la segunda década del Siglo XXI", Informes del GERIUP(11 de enero de 2012).

${ }^{33}$ Ver Richard Killebrew e Jennifer Bernal, Crime Wars: Gangs, Cartels and U.S. National Security. (Washington DC: Center for a New American Security, 2010). 


\section{Mariano César Bartolomé}

interconectadas, culminando en una virtual guerra civil. En consecuencia algunos carteles mexicanos han combinado la violencia de alto nivel, símbolos y rituales religiosos y la acción política para consolidar su control sobre el meganegocio que pretenden dominar. Ellos también buscan la legitimación de la comunidad, cultivando la percepción popular de que son protectores de la sociedad" 34 .

En esta zaga, el aporte conceptual más reciente corresponde a Ioan Grillo, especialista en el estudio de la criminalidad mexicana y centroamericana. En su perspectiva, lo que define a la criminalidad organizada en México como un caso de insurgencia criminal es la voluntad de sus protagonistas de enfrentar al Estado a través de una suerte de rebelión armada que no se sustenta en ningún considerando ideológico. Así, pese a la ausencia de factores ideológicos, la criminalidad mexicana es al mismo tiempo un fenómeno político y paramilitar. Político por su decisión de enfrentar a las fuerzas estatales, en aras de la preservación de sus negocios; paramilitar porque para el logro del mencionado objetivo echan mano a verdaderos ejércitos privados altamente especializados y adecuadamente equipados.

En la visión de este reportero británico, el proceso evolutivo de las organizaciones criminales mexicanas hacia el actual estadio de insurgencia criminal reconoce como punto crítico al año 2006, cuando esos grupos comienzan a aplicar la violencia en forma sistemática y pugnan por controlar el territorio empleando tácticas para infundir terror como se había hecho décadas antes en América Central. Se pasa de una clásica "guerra por las drogas" a una novedosa "guerra por feudos" (la idea de re-feudalización consignada antes por Benítez Manaut) financiada por la droga; la diferencia, aunque sutil, es sumamente importante. Textualmente:

"Las motivaciones de los gángsters definen en muchos aspectos lo que son. Si matan a civiles deliberadamente y con intención, entonces se comportan como terroristas. Si lo que tratan es de tener el monopolio de la violencia en determinado territorio, se

\footnotetext{
${ }^{34}$ Robert Killebrew, "Criminal Insurgency in the Americas and Beyond", Prism 2:3 (2011), 33-52.
} 
comportan como señores de la guerra. Y si están librando una guerra total contra el gobierno, muchos alegarían que son rebeldes o insurgentes" 35 .

Las lecturas arriba descriptas, elaboradas por Lugar, Buscaglia, el CNAS y Grillo, tienen una enorme importancia desde el momento en que deconstruyen y resignifican el concepto de insurgencia. Más allá de sus diferentes abordajes, éste tradicionalmente fue entendido como "el uso prolongado de violencia de baja intensidad para dejar sin efecto un sistema político o forzar algún cambio fundamental en su status quo"36. Por su parte, la definición del Departamento de Defensa estadounidense hace referencia a "el uso organizado de subversión y violencia por un grupo o movimiento que busca sacar u obligar el cambio de una autoridad gobernante" 37 . Una tercera interpretación entiende a un movimiento insurgente como "un conjunto orgánico de hombres que se subleva contra el orden establecido y cuyos objetivos se plasman en documentos básicos"38; en este caso, la lucha armada es la forma en que se canaliza la sublevación, pese a no estar explícitamente mencionada.

En cualquiera de las definiciones que se acaban de consignar, la insurgencia (al igual que el terrorismo) queda englobada dentro de la esfera de la violencia política, entendida como aquella violencia que proviene de agentes organizados que buscan modificar, sustituir o desestabilizar la institucionalidad estatal vigente $^{39}$.

Esa de-construcción y resignificación, de procedencia predominantemente estadounidense, no ha concitado la adhesión de los especialistas mexicanos. En su visión, aun cuando los grupos criminales locales apelan en forma creciente a tácticas terroristas, no pueden ser denominados de esa manera ni como insurgentes debido a una diversidad de motivos, entre ellos

\footnotetext{
${ }^{35}$ Ioan Grillo, El Narco. En el corazón de la insurgencia criminal mexicana. (México DF: Ediciones Urano, 2012)

${ }^{36}$ Usamos aquí la definición simplificada que consta en: Steven Metz, The Future of Insurgency. (Carlisle Barracs: USAWC, Strategic Studies Institute, 2012)

37 "Definición de amenazas", Ágora 4 (2011): 10-13.

${ }^{38}$ Iván Witker, "Del prototerrorismo al narcoterrorismo. Revisando la violencia política en América Latina", Política y Estrategia 96 (2004), 59-82.

${ }^{39}$ Fernando Carrión, "De la violencia urbana a la convivencia ciudadana", in Seguridad Ciudadana, ¿espejismo o realidad, ed. Fernando Carrión. (Quito: FLACSO Ecuador - OPS/OMS, 2002), 13-58.
} 


\section{Mariano César Bartolomé}

los siguientes tres: (i) la criminalidad carece del tipo de reivindicaciones que caracterizan a los grupos insurgentes, que suelen vincularse con algún tipo de identidad colectiva, tienen un contenido político e incluyen alguna propuesta de gobierno; consecuentemente (ii) las bandas criminales no cuentan con una representación simbólica como defensores del pueblo; por último (iii) las insurgencias pueden (y suelen) ser consideradas interlocutores válidos del Estado en el marco de una negociación política tendiente a resolver conflictos armados intraestatales, lo que no acontece con la criminalidad ${ }^{40}$.

Profundizando en este tema, aunque existen numerosos trabajos que abordan la interacción entre violencia política (sea insurgencia o terrorismo) y crimen organizado, usualmente esos aportes sostienen que en este nexo son las primeras las que pueden incursionar en actividades criminales, y no a la inversa. Podemos mencionar dos abordajes analíticos diferentes a la dinámica que se establece entre ambas partes, el primero de los cuales sugiere que el vínculo suele iniciarse a partir de una necesidad específica del insurgente o terrorista, que puede ser de financiación o de equipamiento; sendos ejemplos serían el involucramiento en el narcotráfico o la incursión en el negocio de la comercialización de armas ilegales, respectivamente.

Ciertas características organizacionales y operacionales que comparten la violencia política y la criminalidad facilitan el proceso descripto, entre ellas la racionalidad; el accionar secreto; el desafío al Estado y sus leyes; la asimetría en el empleo de la violencia; y la capacidad de adaptación e innovación. Sin embargo, en ningún momento los insurgentes o terroristas abjuran del carácter político de sus metas, ni renuncian a publicitar y difundir sus acciones, mientras las organizaciones criminales actúan en función de considerandos económicos y buscan mantenerse en el anonimato ${ }^{41}$.

El abordaje analítico alternativo, que no se opone al anterior sino que lo complementa, plantea que aunque la criminalidad organizada y la violencia política son fenómenos diferentes, la creciente interacción entre ambos podría dar lugar a una situación de "convergencia motivacional". En ese proceso de

\footnotetext{
${ }^{40}$ Javier Oliva Posada, “Una embestida conceptual”, Organización Editorial Mexicana, 24 de junio de 2011. Disponible en http://www.oem.com.mx/elsoldemexico/notas/n2120054.htm

${ }^{41}$ Thomas Sanderson, "Transnational Terror and Organized Crime: Blurring the Lines", SAIS Review XXIV:1 (2004), 49-61.
} 
convergencia progresiva, el lucro derivado de las actividades criminales puede llegar a constituir la meta de toda o parte de la organización insurgente o terrorista, aunque no abdique públicamente de sus banderas políticas para no perder legitimidad a los ojos de sus adherentes o seguidores.

Sendos ejemplos concretos de este segundo abordaje serían los taliban afganos y las mencionadas FARC colombianas. En ambos casos los grupos, en determinado momento de su trayectoria, comienzan a cobrar impuestos primero a los campesinos involucrados en el negocio de las drogas, extendiendo posteriormente el cobro de dinero a las actividades de procesamiento y comercialización; como último estadio de este proceso de creciente involucramiento, las mencionadas organizaciones se posicionan como productores de estupefacientes ${ }^{42}$.

En los términos de Makarenko, la referida convergencia motivacional se explica en un "nexo crimen-rebelión" que adopta la forma de un continuo, con la criminalidad en un extremo del espectro, y la insurgencia en el otro, consideradas ambas como fenómenos diferentes. Entre ambos extremos, se presentan las diferentes posibilidades de interacción (Cuadro $\left.\mathbf{N}^{\circ} \mathbf{1}\right)^{43}$.

Frente a este panorama, la verdadera importancia de la resignificación del concepto de insurgencia por parte de Lugar, el CNAS y Grillo radica en que le quita su tradicional connotación política, enfatizando en su efecto más nítido, debilitar o impedir las funciones de un gobierno, sobre todo su control sobre ciertos espacios territoriales, independientemente de su meta última ${ }^{44}$. En sentido diametralmente opuesto a los planteos tradicionales, no se asiste aquí a una incursión de organizaciones insurgentes en el campo de la criminalidad, sino exactamente lo contrario.

\footnotetext{
42 "Crimen e Insurgencia”, Agora 4:2 (2011).

${ }^{43}$ Cornell, Svante (2007). Narcotics and Armed Conflict. Interaction and Implications. Studies in Conflict \& Terrorism 30:3 (March), pp. 207-227

${ }^{44}$ Richard Killebrew y Jennifer Bernal, Crime Wars: Gangs, Cartels and U.S. National Security. (Washington DC: Center for a New American Security, 2010), 5-7; Ioan Grillo, El Narco. En el corazón de la insurgencia criminal mexicana. (México DF: Ediciones Urano, 2012).
} 


\section{Mariano César Bartolomé}

\section{Cuadro $N^{\circ}$ 1: Nexo Crimen-Rebelión}

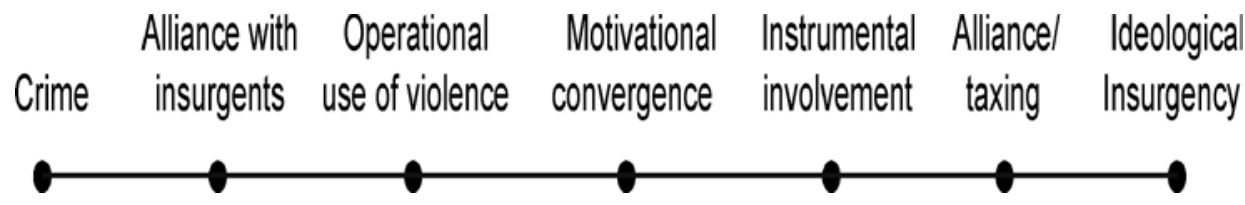

\section{El escenario sudamericano frente al nuevo enfoque de la Insurgencia}

Un abordaje al escenario actual de Sudamérica en materia de insurgencia, desde una perspectiva tradicional de ese concepto, se hubiera limitado a dos casos residuales de otras épocas, y al mismo tiempo verdaderos resabios de la Guerra Fría: por un lado, las FARC en el país homónimo; por otra parte, Sendero Luminoso (SL) en Perú. Ambas organizaciones hace tiempo comenzaron a incursionar en el campo de la criminalidad, desnaturalizándose en forma progresiva, al punto de ser habitualmente tipificadas en esta última esfera.

En relación a las FARC su viraje hacia la criminalidad organizada comenzó a principios de la década del 90, en el marco de una reorientación generada tras la muerte de su líder Jacobo Arenas, quien mantenía la pureza ideológica y doctrinaria de la organización. Ese proceso estuvo enmarcado en una profunda reorganización del escenario de criminalidad colombiana originada por la derrota y desmembramiento de los míticos carteles del narcotráfico de Cali y Medellín. A mediados de ese decenio la justicia de ese país actuó en consonancia con ese cambio y emitió casi medio centenar de órdenes de captura contra jerarcas y mandos intermedios del grupo, por tráfico de drogas. El listado incluía al fundador y jefe máximo de la organización, Manuel Marulanda Vélez (alias "Tirofijo"); Luis Edgar Devia ("Raúl Reyes"); Luciano Marín ("Iván Márquez"); Guillermo Sánchez Vargas ("Alfonso Cano") y Jorge Briceño Suárez ("Mono Jojoy").

Se ha dicho de las FARC que en otras épocas fueron una insurgencia ideológica pero luego se transformaron en una "gavilla criminal de narcotraficantes con expresiones brutales de terrorismo contraproducente". Ampliando esta idea, dijo el salvadoreño Joaquín Villalobos: "Comenzaron extorsionando narcotraficantes y terminaron siendo dueños de la mayor 
producción de cocaína del mundo. Transitaron de última guerrilla política latinoamericana a primer ejército irregular del narcotráfico"45. Lo notable de esta última frase es que no fue emitida por un funcionario del gobierno colombiano, sino por un viejo líder del Frente Farabundo Martí de Liberación Nacional (FMLN), desencantado con la mutación de la organización hacia las actividades criminales.

Abundan las evidencias del nivel de complejidad y transnacionalidad que alcanzaron las acciones criminales de las FARC. Esas constancias se incrementaron dramáticamente a partir de la información obtenida de los computadores personales de Raúl Reyes, encontrados en el campamento de Angostura donde fue abatido ese jefe insurgente, en la Operación Fénix que hemos mencionado en la parte inicial del presente trabajo ${ }^{46}$.

En este sentido, pueden mencionarse los vínculos con grupos criminales de Brasil; el tráfico de armas en Perú, donde además coordinan acciones con SL, cultivan coca en los territorios amazónicos, y reclutan forzadamente aborígenes; la instalación de santuarios en Ecuador y Venezuela; la legalización de activos procedentes de actividades ilícitas en Costa Rica y otras naciones centroamericanas; en México, el vínculo con los carteles criminales y con el Ejército Popular Revolucionario (EPR); la ejecución de secuestros extorsivos en Paraguay, operando combinadamente con el partido Patria Libre; los lazos con la organización separatista vasca ETA y con el Ejército Republicano Irlandés (IRA); los contactos con el recientemente derrocado líder libio Muammar Kaddafi, orientados a la adquisición de misiles antiaéreos; la vastísima red de ONG's europeas que le brindan respaldo y promueven su ideario (el oficial, no el

45 Álvaro Valencia Tovar, "Las FARC se desintegran", El Tiempo, 14 de marzo de 2008; Joaquín Villalobos, "Las FARC, um decadente club de narcos y bandidos", La Nación (Buenos Aires), 18 de enero de 2008 .

${ }^{46}$ Consideramos verídicos los reportes emitidos por el gobierno colombiano respecto a la información contenida en las computadoras personales de Raúl Reyes, y también consideramos fiable la verificación efectuada por INTERPOL, cuyos detalles son públicos. Ver en este sentido: OIPC-INTERPOL, Informe forense de Interpol sobre los ordenadores y equipos informáticos de las FARC decomisados por Colombia.(Lyon: OIPC-INTERPOL, 2008) 


\section{Mariano César Bartolomé}

criminal, por supuesto), y el sostén de las fuerzas políticas latinoamericanas nucleadas en la Coordinadora Continental Bolivariana (CCB).

En los últimos cuatro años las FARC sufrieron las peores derrotas de toda su historia. En febrero del año 2008 falleció su fundador y líder Tirofijo; al mes siguiente tuvieron el mismo desenlace Raúl Reyes e Iván Ríos, ultimado por su propio guardaespaldas; el "Mono Jojoy" fue muerto en septiembre de 2010, y Alfonso Cano en octubre de 2011. Por su parte Nelly Ávila Moreno ("Karina"), la máxima jefa mujer de la banda, se entregó a las autoridades en mayo de 2008 en estado de desnutrición, para efectuar luego un llamado público a sus antiguos camaradas, a que depongan las armas y se reintegren a la sociedad. A estos reveses debe agregarse la "Operación Jaque" de rescate a una docena de rehenes del grupo, incluyendo la dirigente política y ex candidata presidencial Ingrid Betancourt, a mediados del año 2008. En todo este proceso, miles de insurgentes desertaron de las filas de la organización, que perdió capacidad para efectuar grandes operaciones y debió contentarse con golpes aislados y esporádicos.

A fines del año pasado, el Comando de las Fuerzas Militares de Colombia estimó que en las filas de las FARC no quedaban más de 9 mil efectivos, cifra que suponía una reducción del $50 \%$ en el cuerpo de esa organización frente a la cantidad que tenía hace ocho o nueve años ${ }^{47}$. En ese contexto comenzaron a proliferar los análisis que especulaban con la derrota definitiva de este grupo en el corto plazo ${ }^{48}$, o su aceptación de negociaciones directas con el gobierno, desde una posición de debilidad.

Precisamente, sendas delegaciones del gobierno colombiano y las FARC llevaron adelante diálogos exploratorios en estricto secreto en Cuba entre febrero y agosto del presente año, que culminaron con la firma de un acuerdo a través del cual se inauguraron negociaciones públicas y oficiales entre las partes, en Oslo.

Respecto a Sendero, este grupo armado surgió con impronta maoísta a comienzos de los años 80 y ha sido señalado por la Comisión de la Verdad y la Reconciliación de Perú como el responsable de más de la mitad de las 70 mil

\footnotetext{
${ }^{47}$ FARC están reducidas al 50\% frente a hace 8 años, $A B C$ (Asunción) 18 de diciembre de 2011

${ }^{48}$ Ver por ejemplo: Eduardo Posada Carbo, “¿El fin de las FARC?”, Infolatam, 6 de noviembre de 2011.
} 
víctimas mortales que dejó la guerra interna que se desarrolló en ese país en las últimas dos décadas del siglo pasado ${ }^{49}$. Luego de la detención de sus principales líderes la organización quedó prácticamente desarticulada, pero hace poco más de un decenio un remanente comenzó a operar en la selvática zona del Valle de los Ríos Apurimac y Ene (VRAE). Ese senderismo residual se vinculó cada vez más con el negocio del narcotráfico, obteniendo de esa manera fondos para sostener sus operaciones y adquirir armamento.

En el marco de ese proceso de criminalización, los senderistas evolucionaron de la protección a la droga que era trasladada fuera de esa zona del departamento de Ayacucho, a la participación directa en el sembrado de la hoja de coca, su cosecha y posterior transformación en clorhidrato de cocaína. Hace pocos años un dossier elaborado por el ministerio de Defensa aseguraba que SL se comporta “como una firma más dedicada al tráfico ilícito de drogas en el VRAE". Esa perspectiva fue ratificada por su titular Ántero Flores-Aráoz, quien sostuvo que el componente ideológico de los senderistas se había diluido en función de una "asociatividad" con el narcotráfico ${ }^{50}$.

A mediados de la década pasada, el remanente senderista extendió sus actividades más allá de Perú, confirmando su transnacionalidad. Así, comenzó a practicar robos a bancos en Bolivia y a vender droga en barrios de clase baja de la ciudad de Buenos Aires ${ }^{51}$. Al mismo tiempo, retomó las acciones armadas en el VRAE con crecientes niveles de violencia, incluyendo ataques a efectivos militares y policiales; la capacidad que llegó a adquirir el grupo quedó evidenciada a fines del año 2009, cuando derribó en plena selva un helicóptero

\footnotetext{
49 SL fue creado por el profesor Abimael Guzmán a finales de la década de los sesenta con una clara filosofía maoísta, y siempre se ha autodenominado 'Partido Comunista del Perú. Siempre ha buscado reemplazar las instituciones con un régimen revolucionario campesino comunista. En los años 70 el movimiento tuvo un fuerte arraigo en varias universidades, entre ellas la Universidad Nacional de San Cristóbal de Huamanga, donde Guzmán dictó filosofía. Luego de su apogeo en los años 80, su ocaso se precipitó en 1992 con la detención de su fundador y máximo líder, y otros altos jefes.

${ }^{50}$ Mariano Bartolomé, "Violencia armada y criminalidad organizada en América del Sur. Situación y perspectivas de Sendero Luminoso y las FARC", Mundo Relações Internacionais, 26 de mayo de 2010. Disponible en: http://www.mundori.com/home/view.asp?paNoticia=1860 .

51 "Senderistas se capitalizan en Bolivia", La Razón, 07 de marzo de 2009; Leonardo de Corso y Virginia Messi, “Cómo funciona el mayor centro de venta de drogas, Clarín, 18 de abril de 2010.
} 


\section{Mariano César Bartolomé}

militar Mi-17 de fabricación rusa, mediante el uso de una ametralladora antiaérea de $12,7 \mathrm{~mm}$ y lanzagranadas RPG.

Por su parte, el gobierno comenzó a emplear en forma intensiva a sus Fuerzas Armadas para combatir este flagelo, ejecutando operaciones de gran envergadura. Esas acciones se llevaron a cabo con gran dificultad y un éxito limitado, que un especialista peruano atribuyó a la evolución de las tácticas y procedimientos de SL, más rápida que la actualización de la doctrina militar de su país; en este sentido, traza paralelismos con la conducta de EEUU en Afganistán. En sus palabras:

\footnotetext{
"Para cualquier Fuerza Armada, la doctrina viene a ser el equivalente al software que va aplicarse a través de su hardware, que es todo su equipamiento. La doctrina es muy importante porque te dice cómo va a pelear una determinada organización, si fuera el caso de tener que enfrentar a un enemigo no estatal y asimétrico, como efectivamente sucede en el VRAE" 52 .
}

La actualización de la doctrina militar peruana, especialmente en materia de combate asimétrico, recolección y análisis de información de combate y accionar conjunto, proporcionó su mejor efecto en febrero de este año, cuando fue capturado (gravemente herido, luego de un combate con las fuerzas gubernamentales) el llamado "Camarada Artemio", máximo líder de SL en el VRAE. Más allá de ese contundente golpe, al momento de cierre de esta ponencia el criminalizado remanente senderista no ha depuesto las armas.

Sin embargo, la situación de América del Sur en términos de insurgencia es completamente diferente de lo expresado en los párrafos precedentes, si se trasciende el enfoque tradicional de ese concepto y se adopta la lectura elaborada a partir del agravamiento de la cuestión mexicana. En ese caso, en el espacio sudamericano las insurgencias vigentes aumentan de dos a cuatro, existiendo la posibilidad de incluir un quinto episodio. A las ya mencionadas FARC y SL se agregan las llamadas Bandas Criminales Emergentes (BACRIM)

${ }^{52}$ Alberto Bolívar Ocampo, “Afganistán y el VRAE”, Actualidad Militar 471 (2011). 
en Colombia, las organizaciones criminales asentadas en las grander urbes de Brasil e incluso el Ejército Popular Paraguayo (EPP).

Las BACRIM fueron tipificadas como el nuevo enemigo armado del Estado por parte del Ministerio del Interior y de Justicia colombiano. El narcotráfico es la piedra basal de las actividades de estas bandas, cuyo origen se remonta al año 2006, cuando culminó el proceso de desarme y desmovilización de los grupos paramilitares nucleados en las Autodefensas Unidas de Colombia (AUC), fruto de un acuerdo con el entonces presidente Álvaro Uribe. Los integrantes de los grupos que no aceptaron el convite gubernamental y se mantuvieron fuera de la ley se reorganizaron en nuevas entidades criminales que hoy totalizan aproximadamente unos $7 \mathrm{mil}$ efectivos. Las bandas más importantes a nivel nacional, tomando en cuenta tanto sus dimensiones como su territorial, son los Paisas, Rastrojos, Urabeños, Ejército Revolucionario Popular Antiterrorista Colombiano (ERPAC), Nueva Generación y Águilas Negras.

Respecto a Brasil, en las favelas de sus urbes más populosas, sobre todo Río de Janeiro y San Pablo, se encuentran las bases de numerosas organizaciones criminales consagradas principalmente al tráfico de drogas, y en forma subsidiaria a otras actividades ilegales como prostitución, juego clandestino, tráfico de armas, contrabando y extorsión.

Es tal la dimensión y el poderío de estos grupos, entre los cuales se destacan el Comando Vermelho carioca y el Primer Comando de la Capital paulista, que las operaciones que monta el Estado para descabezarlos insumen cientos de efectivos policiales especializados, respaldados en aspectos logísticos por las Fuerzas Armadas. En este sentido, las operaciones contra la criminalidad desarrolladas en el último bienio en las favelas Vila Cruzeiro, Complejo Alemão o Rocinha fueron ejecutadas por unidades policiales estaduales y federales que ingresaron a esas barriadas a bordo de vehículos blindados de la Infantería de Marina.

Finalmente, el EPP es fruto del reagrupamiento de antiguos miembros del Partido Patria Libre. Aunque se autodefine como revolucionario de principios marxistas-leninistas, con elementos ideológicos asociados a las ideas del caudillo local Francisco Solano López, sus actividades están claramente orientadas al lucro mediante la realización de secuestros extorsivos a 


\section{Mariano César Bartolomé}

importantes ganaderos. Las autoridades paraguayas aseguran que el grupo está vinculado con las FARC colombianas y sus miembros han reciben de la contraparte entrenamiento en combate rural y ejecución de secuestros.

A partir de la invasión de esa organización a una estancia que culminó con el asesinato de cuatro personas, hace aproximadamente un lustro, el Poder Ejecutivo impulsó distintos operativos policiales y militares en la zona norte del territorio nacional. Las iniciativas incluyeron el despliegue de miles de efectivos que, sin embargo, no lograron detener a los principales líderes del grupo. Mientras tanto, el tema comenzó a generar preocupación en el gobierno y los legisladores de Brasil, por el "derrame" que podría generarse sobre el propio territorio. Una medida de esa inquietud fue proporcionada por el ex presidente José Sarney, quien admitió temer que un crecimiento de las actividades del EPP produzca una "colombianización" del Paraguay ${ }^{53}$.

\section{Algunas Conclusiones}

Dentro del panorama de seguridad latinoamericano, los bajos niveles de conflictividad que se registran en términos westfalianos coexisten con una dinámica y heterogénea agenda en materia de amenazas no convencionales. Estas amenazas se despliegan en forma transnacional y están protagonizadas por actores no estatales que emplean la violencia, en tanto herramienta racional de política, en forma asimétrica. En este marco, la criminalidad organizada ocupa un lugar de preponderancia, destacándose el área andina como zona de producción de cocaína, y México y el istmo centroamericano configurando un corredor del tráfico de esa droga hacia EEUU, el principal mercado de consumo del mundo.

En este marco, el incremento y la complejización de la criminalidad organizada en México ha fomentado la aparición de una corriente de pensamiento que resignifica el concepto de insurgencia, a fin de aplicarlo al caso azteca. La resignificación de la insurgencia soslaya la naturaleza política de las metas de quienes la protagonizan, relativizando así su encuadre dentro de la

\footnotetext{
${ }^{53}$ Mariano Bartolomé, "Secuestros extorsivos y reivindicaciones campesinas: la rara alquimia del Ejército Popular Paraguayo", Analítica, 05 de mayo de 2010. Disponible en: http://www.analitica.com/va/internacionales/opinion/3857731.asp
} 
esfera de la violencia política. Al mismo tiempo, no repara en los enfoques tradicionales que entienden que en caso de vínculos entre insurgencia y criminalidad, es el primero de esos factores el que muta a efectos de incursionar en el campo del segundo.

El enfoque resignificado de la insurgencia enfatiza en su efecto de debilitamiento o impedimento del adecuado ejercicio de las funciones de un gobierno, en especial su control efectivo sobre todo el territorio nacional. Los aspectos instrumentales de la insurgencia ocupan el centro de la cuestión, desplazando de esa posición a la cuestión de la naturaleza de las metas perseguidas. En esta confluencia entre insurgencia y criminalidad, es el segundo de los factores el que adopta la fisonomía del primero.

Una aplicación de esta nueva conceptualización de la insurgencia, surgida al calor del deterioro de la situación de México en materia de criminalidad, al análisis del panorama de seguridad sudamericano genera importantes repercusiones. Desde un punto de vista cuantitativo, los habituales diagnósticos que coinciden en la existencia de dos insurgencias residuales signadas cada vez más por una impronta narcoterrorista, las FARC y SL, dejan lugar a otras lecturas que elevan los casos de insurgencias a no menos de cinco: a los farianos y senderistas se agregan las BACRIM, organizaciones brasileñas que operan desde las favelas de las mayores urbes del país, y el EPP paraguayo.

Cualitativamente, el análisis de América del Sur a través del prisma de la nueva interpretación de la insurgencia permite arribar a por lo menos tres importantes conclusiones. Primero, establece que la insurgencia sudamericana no es un fenómeno en declive sino, por el contrario, en nítido crecimiento; segundo, deja de circunscribir la insurgencia a la zona andina, con las particularidades geográficas y culturales que ello supone, para hacerla extensiva a otros puntos de la región; finalmente, también en términos espaciales, deja de concebirla como un fenómeno casi exclusivamente rural, para incorporar al análisis los entornos urbanos.

Más allá de estos cambios cuantitativos y cualitativos, una eventual consolidación de los nuevos enfoques sobre insurgencia puede generar otros efectos en América del Sur. Primero, en lo relativo al empleo del instrumento militar, siendo que no es lo mismo ese uso en un mero combate contra la criminalidad que contra un adversario que le disputa al Estado el control 


\section{Mariano César Bartolomé}

territorial y el ejercicio de la autoridad; segundo, en lo que hace al tipo de tratamiento que le otorgan los gobiernos a estos fenómenos, ya que la resolución de un caso de insurgencia puede derivar en un trato "político" con la contraparte, opción a la que normalmente no tienen acceso los grupos criminales; tercero, las nuevas perspectivas pueden generar repercusiones tanto doctrinarias como de cooperación en materia de seguridad, sobre todo en el marco de instituciones multilaterales, como podría ser el caso del Consejo de Defensa Sudamericano (CDS) de la UNASUR. 


\section{REFERENCIAS}

Ayala, Ruben Luis. “¿Es un ataque de los Zetas a EEUU sólo una cuestión de tiempo?" $\begin{array}{lllll}\text { Ágora, } & 19 & \text { de } & \text { octubre } & \text { de }\end{array}$ http://www.agorarevista.com/es/articles/rmim/features/online/2011/10/19/iranzetas-plot

Banco Mundial. Crimen y Violencia en Centroamérica. Un Desafio para el Desarrollo. Washington DC: Banco Mundial, 2011.

Bartolomé, Mariano. "Situación del Crimen Organizado en América Latina." Ágora Internacional 10 (2009).

"Secuestros extorsivos y reivindicaciones campesinas: la rara alquimia del Ejército Popular Paraguayo." Analítica, 05 de mayo de 2010. http://www.analitica.com/va/internacionales/opinion/3857731.asp

"Violencia armada y criminalidad organizada en América del Sur. Situación y perspectivas de Sendero Luminoso y las FARC." Mundo Relações Internacionais, 26 de mayo de 2010. http://www.mundori.com/home/view.asp?paNoticia=1860

Benítez Manaut, Raúl. "La crisis de seguridad de México." Nueva Sociedad 220 (2009).

Bolívar Ocampo, Alberto. “Afganistán y el VRAE." Actualidad Militar 471 (2011).

Briscoe, Iván. "Crimen y drogas en los Estados Frágiles." Fundación para las Relaciones Internacionales y el Diálogo Exterior (FRIDE), 25 de julio de 2007. http://www.fride.org/publicacion/151/crimen-y-drogas-en-los-estados-fragiles

Carrión, Fernando. "De la violencia urbana a la convivencia ciudadana". In Seguridad Ciudadana, ¿espejismo o realidad?, editado por Fernando Carrión. Quito: FLACSO Ecuador - OPS/OMS, 2002.

Comisión Latinoamericana sobre Drogas y Democracia. Drogas y Democracia: hacia un cambio de paradigma. Rio de Janeiro: Viva Río \& Comisión Latinoamericana sobre Drogas y Democracia, 2009.

Consejo Ciudadano para la Seguridad Pública y la Justicia Penal. Metodología del ranking (2011) de las 50 ciudades y las 50 jurisdicciones subnacionales más violentas del mundo. México DF: CCSP, 2012.

Cornell, Svante. "Narcotics and Armed Conflict. Interaction and Implications." Studies in Conflict \& Terrorism 30 (2007).

GERIUP. "La Conferencia Internacional de Apoyo a la Estrategia de Seguridad de Centroamérica." Informes del GERIUP, 29 de junio de 2011.

GERIUP. "Criminalidad y violencia en América Latina iniciando la segunda década del Siglo XXI". Informes del GERIUP, 11 de enero de 2012.

Grillo, Ioan. El Narco. En el corazón de la insurgencia criminal mexicana. Mexico DF: Ediciones Urano, 2012.

Gualdoni, Fernando and Javier Lafuente. "Las armas ilegales desangran Latinoamérica." EI País, 25 de mayo de 2009. 


\section{Mariano César Bartolomé}

Heidelberg Institute for International Conflict Research (HIIK). Conflict Barometer 2010.

HIIK,

2010.

http://www.hiik.de/en/konfliktbarometer/pdf/ConflictBarometer_2010.pdf

Khalizad, Zalmay. "Losing the Moment? The United States and the World after the Cold

War." In Order and Disorder after the Cold War, editado por Brad Roberts. Cambridge and London: The MIT Press, 1995.

Killebrew, Robert. "Criminal Insurgency in the Americas and Beyond." Prism 2 (2011): 3352.

Killebrew, Robert \& Jennifer Bernal. Crime Wars: Gangs, Cartels and U.S. National Security. Washington DC: Center for a New American Security, 2010.

Lutes, Charles, Elaine Bunn, and Stephen Flanagan. "The Emerging Global Security Environment." In Strategic Challenges: America's Global Security Agenda, editado por Stephen Flanagan and James Schear. Washington DC: National Defense University Press \& Potomac Books, 2008.

Metz, Steven. The Future of Insurgency. Carlisle Barracks: USAWC, 1993.

OIPC-INTERPOL, Informe forense de Interpol sobre los ordenadores y equipos informáticos de las FARC decomisados por Colombia. Lyon: OIPC-INTERPOL, 2008.

Oliva Posada, Javier. “Una embestida conceptual." Organización Editorial Mexicana, 24 de junio de 2011. http://www.oem.com.mx/elsoldemexico/notas/n2120054.htm

Pabón Ayala, Natalie. "Las relaciones cívico-militares en la Política de Seguridad

Democrática." In Perspectivas actuales de la Seguridad y la Defensa en Colombia y América Latina, editado por Alejo Vargas Velásques. Bogotá: Universidad Nacional de Rosario, 2008.

Posada Carbo, Eduardo. “¿El fin de las FARC?” Infolatam, 06 de noviembre de 2011.

Sanderson, Thomas. "Transnational Terror and Organized Crime: Blurring the Lines." SAIS Review XXIV (1), 2004.

Tello, Ángel. "La Incertidumbre Estratégica." In Seguridad y Defensa en tiempos de Bicentenario. Visiones desde Argentina y Chile, organizado por Mariano Bartolomé. Buenos Aires: Instituto de Publicaciones Navales, 2010.

United Nations Office on Drugs and Crime. The Globalization of Crime. A Transnational /Organized Crime Threat Assessment. Viena: UNODC, 2010.

. World Drug Report. Viena: UNODC, 2011.

2011 Global Study on Homicide. Trends, Context, Data. Viena: UNODC, 2011.

Valencia Tovar, Álvaro. "Las FARC se desintegran." El Tiempo, 14 de marzo de 2008.

Vázquez Montalbán, Manuel. Foreword to "Notas sobre globalizadores y globalizados." In

Geopolitica Del Caos, by multiple authors, 15. Barcelona: Le Monde Diplomatique/Temas de Debate, 1999.

Villalobos, Joaquín. "Las FARC, un decadente club de narcos y bandidos." La Nación

(Buenos Aires), 18 de enero de 2008.

. "La fuerza de México." Nexos, 01 de marzo de 2009. 
Witker, Iván. "Del prototerrorismo al narcoterrorismo. Revisando la violencia política en América Latina." Política y Estrategia 96 (2004).

Woodeward, Susan. "Fragile States: Exploring the Concept." Fundación para las Relaciones Internacionales y el Diálogo Exterior (FRIDE), 16 de diciembre de 2006. http://www.fride.org/publication/97/fragile-states:-exploring-the-concept 


\section{Mariano César Bartolomé}

\section{RESUMEN}

El espacio geográfico latinoamericano es pródigo en amenazas no convencionales a la seguridad de sus Estados, las sociedades que los componen y los individuos que las integran. Esas amenazas se caracterizan por su dinámica transnacional, el carácter no estatal de sus protagonistas y su empleo de la violencia en formatos asimétricos.

Dentro de ese panorama se destaca la criminalidad organizada, que está presente en todas las regiones del hemisferio, presentando en cada caso características diferenciadas. En este panorama se destaca por su gravedad el caso de México, que ha sido tipificado por centros de estudios y expertos como ejemplo de una nueva forma de insurgencia. Esas lecturas obligan a una reconceptualización del concepto de insurgencia, definiéndolo más por la cuestión del control territorial que por la motivación política de sus actos.

A partir del panorama descripto el objetivo del presente trabajo ${ }^{54}$ es aplicar el concepto reformulado de insurgencia al escenario sudamericano. A ese efecto, se establecerán los alcances de ese concepto, identificaremos casos concretos de aplicación, su impacto en el entorno estratégico regional y en la cooperación multilateral en materia de seguridad.

\section{PALABRAS GLAVE}

Seguridad; América del Sur; Crimen Organizado; Insurgencia.

Recebido em 19 de novembro de 2012. Aprovado em 15 de dezembro de 2012.

\footnotetext{
54 Versiones preliminares del presente trabajo fueron presentadas en el LIV Congreso Internacional de Americanistas, "Construyendo Diálogos en las Américas", Viena julio de 2012, y en la III Jornada de Relaciones Internacionales, Facultad Latinoamericana de Ciencias Sociales (FLACSO), Buenos Aires, 2526 de octubre de 2012.
} 